International Journal of Physical Sciences and Engineering
Available online at http://sciencescholar.us/journal/index.php/ijpse
Vol. 3 No. 2, August 2019, pages: $21 \sim 26$
e-ISSN : 2550-6943, p-ISSN : 2550-6951
https://doi.org/10.29332/ijpse.v3n2.325

\title{
Technical-Economic Impact of Low Voltage Secondary Lines To Pre-Assembled
}

\author{
$\underset{\text { CrossMark }}{\text { Cricu updente }}$

\begin{abstract}
Steven Ruben Briones Giler a, Carlos Javier Sailema Loor b, Jean Carlos Maciás Moreira c, Bryan Alexander Muñoz Zambrano ${ }^{d}$
\end{abstract}

Article history: Received 27 December 2018, Accepted: 30 April 2019, Published: 29 August 2019

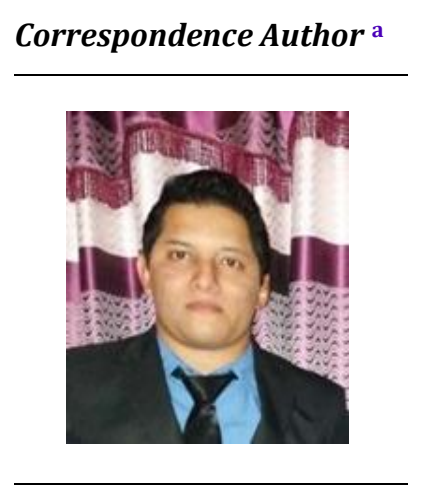

Keywords

energy;

low voltage;

materials;

pre-assembled;

technical-economic;

\begin{abstract}
Distributed generation is understood as all those sources of electrical energy that are connected in the electricity distribution networks. These distribution networks have been planned with wide operating margins, which together with the characteristic that energy flows are unidirectional (from the substation to consumers) allow them to be operated passively. This means that they are not subject to constant monitoring of the network status variables (ie voltages, flows), so these networks are managed with little supervision since that is more economical. The objective of this research is to investigate the economic impact that is presented within the university for a better presetting in the low voltage lines for them, the causes and effects that can be committed when installing them have been investigated, in addition to making a bibliographic review of how in other countries and within our city Portoviejo is distributed in low voltage and its consequences or benefits.
\end{abstract}

e-ISSN: 2550-6943, p-ISSN: 2550-6951 ๑Copyright 2019. The Author. SS Journals Published by Universidad Técnica de Manabí. This is an open-access article under the CC BY-SA 4.0 license (https://creativecommons.org/licenses/by-sa/4.0/) All rights reserved.

\section{Contents}

Abstract

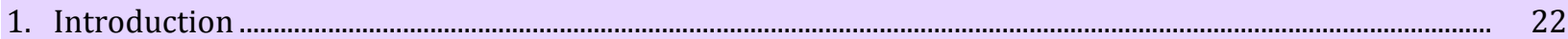

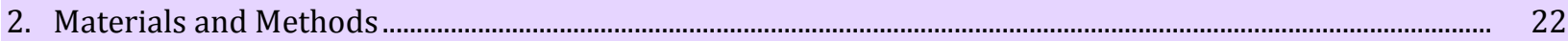

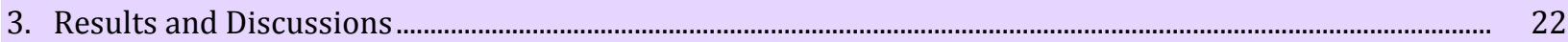

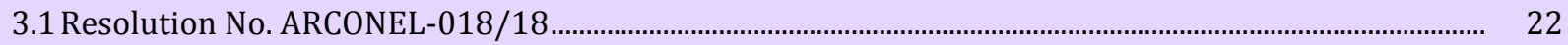

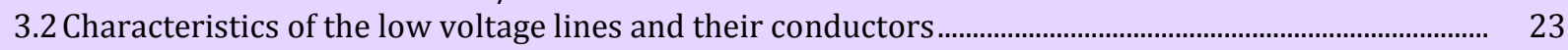

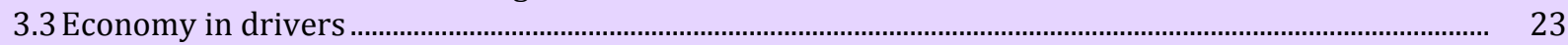

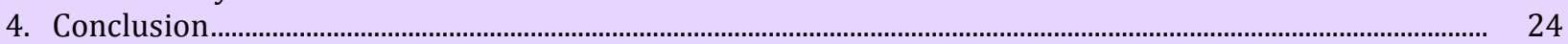

a Universidad Técnica de Manabí, Portoviejo, Ecuador

b Universidad Técnica de Manabí, Portoviejo, Ecuador

c Universidad Técnica de Manabí, Portoviejo, Ecuador

d Universidad Técnica de Manabí, Portoviejo, Ecuador 


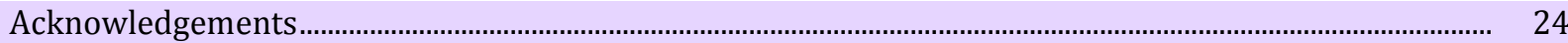

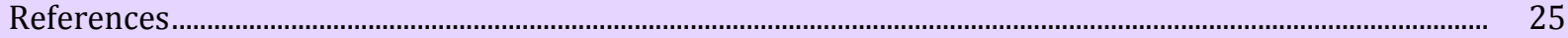

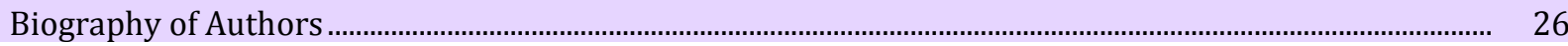

\section{Introduction}

This article begins with a review of the configurations of power distribution networks used in different parts of the world. The transfer function for different sections in isolated low voltage networks will then be analyzed, radiation caused by PLC technology and the effect of electromagnetic interference with radio frequency communications, especially in some specific bandwidths, will be considered. A model of the PLC channel that includes some of its main characteristics is also proposed, and finally, the article closes with the pertinent conclusions (Mora, 2005).

Low voltage networks make up the final stage within the electricity supply chain, finally connecting all regulated customers, which although have reduced individual power requirements, together form an important block of energy demand electrical for the distribution system (Aguirre, 2007).

The selection of insulated cables have different advantages, by reducing the short circuits between conductors, which normally cause interruptions of the service, and the problems of wooded areas are solved, not only by the contacts that the branches can cause, but also by the greater resistance from the cable assemblies to the fall of them or even trees.

Since it is possible to bring the conductors closer until the cables are in contact, the lines have a significantly lower reactance (of the order of the third part) than the networks with bare conductors. As in the low voltage distribution, the limiting condition is the voltage drop, it is possible to increase the transmission capacity to such an extent that in certain cases insulated cables with conductors of a smaller section than those placed on insulators can be provided.

\section{Materials and Methods}

In the beginning, the lines were direct current (single voltage), it is not known whether because Edison ignored the advantages of alternating current indicated, among others, by his employee Nicolas Tesla or because his partner Morgan controlled, the copper market, and to electrify New York in direct current it was necessary to bury a lot (Miravalles, 2016).

Electricity is a vitally important input for the economy because it is used practically in the production of all goods or services, as well as in the daily activities of any person. The demand for electricity has grown rapidly, along with technological development and the advancement of computer and communications systems. Therefore, per capita, electricity consumption goes in direct proportion to economic development (Rivero, 2010).

With the passing of time, different types of regulations have been increased for the electrical engineer, workers in the electrical system and construction regulations. According to the electricity management agreement in Ecuador.

\section{Results and Discussions}

\subsection{Resolution No. ARCONEL-018/18}

That, Article 83 of the LOSPEE, in its pertinent part, provides that "... The Ministry of Electricity and Renewable Energy or companies public of provision of the public service of electrical energy, they will be able to establish easements for the infrastructure of lines of transmission and electrical distribution and other own facilities of the electrical service"; Performing recycling and solid waste activities is essential because they generate biogas, composed of almost $50 \%$ methane. It is known because it is one of the gases involved in 
climate change. It is important for Ecuador and other countries of the world because collecting solid waste creates another type of sustainable energy.

That, through Ministerial Agreement No. 01-245 of July 13, 2001, published in the Official Registry No. 382 of August 2, 2001, the Ecuadorian Code of Practice CPE INEN 19 (National Electrical Code) was issued. This code provides that the National Electric Safety Code, ANSI C2, be used for safety distances in installations of more than $600 \mathrm{~V}$ nominal;

That, in the Official Registry Number 41 of March 14, 2007, the environmental technical standards for the prevention and control of environmental pollution related to electrical infrastructure, telecommunications and transport (ports and airports), contained in Annex 10 were published denominated "Standard of NonIonizing Radiation of Electromagnetic Fields", same as in its Table No. 2 it establishes the width of the easement strips for lines with voltage levels of $69 \mathrm{kV}, 138 \mathrm{kV}$ and $230 \mathrm{kV}$ (Widharma, 2017).

\subsection{Characteristics of the low voltage lines and their conductors}

Voltages below $1 \mathrm{kV}$ that are further reduced so that they can be used in industry, street lighting, and home. The tensions most used in the industry are 220, 380 and 440 volts of alternating current and in homes between 110 and 120 volts for most of the countries of America and 220 volts for Europe.

It should be noted that the tensions that are used in the industry and that that reaches our homes are alternating (AC), whose frequency in America is $60 \mathrm{Hertz}(\mathrm{Hz})$, and in Europe $50 \mathrm{Hertz}$

The method of transporting and / or Distribution of electricity is by means of bare aerial cables that are not supported by towers/ poles, we will discuss the types of towers or poles most used in low and high voltage lines (Miravalles, 2010).

Injections, withdrawals or failures of each power generator affect the costs incurred by other network operators and may result in interruptions or fluctuations in the frequency or voltage of the electric current. Additions to the transmission network benefit both generators and consumers. The transmission has network externalities that can be positive or negative.

Current electricity transmission networks are technically capable in the efficient use of power plants dispersed throughout a territory. It is possible to substitute in real time the production of plants with high costs, with that of plants with lower marginal costs. It is also feasible to save the required reserve capacity, to reach a certain level of reliability in the network.

The distribution networks of medium and low voltage are characterized by presenting economies of density that justify the granting of exclusive rights over territory. Distribution has characteristics similar to a transmission, although in this case there may be several regional monopolies (Rivero, 2010).

\subsection{Economy in drivers}

The most economical driver is determined by scoring on various sections, and it is the one for which the sum of the annual cost of energy losses and annual financial charges is minimal. Such comparison, made for fixed conditions, that is, for a given value and character of the load, type of construction, transmission distance, and voltage, can include all costs without taking into account how little or many such costs are affecting. The driver section. But if the most economical driver section is determined by formulas such as those indicated in the following paragraph, it is necessary that all costs affected by the driver section be included in $\mathrm{P}$, cost per unit of weight.

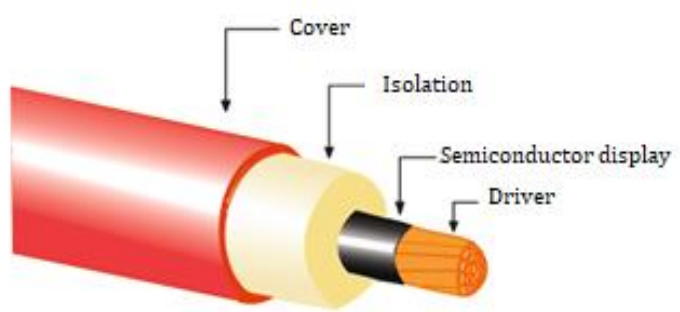

Figure 1. Design of a single-conductor cable for voltages between $2 \mathrm{kV}$ and $5 \mathrm{kV}$

Giler, S. R. B., Loor, C. J. S., Moreira, J. C. M., \& Zambrano, B. A. M. (2019). Technical-economic impact of low voltage secondary lines to pre-assembled. International Journal of Physical Sciences and Engineering, 3(2), 21-26. 
The pre-assembled cable will consist of multiple phases and/ or lighting conductors, whose function is only electric, and a neutral conductor that also assumes the mechanical function. The conductors for the phases will be of pure aluminum or soft copper, and the carrier of aluminum alloy or hard copper, as indicated later in this specification. The insulation of all conductors will be through a layer of cross-linked polyethylene (XLPE) (ENDESA, 2007).

The material of the neutral bearing conductor will be made of ASTM6201 aluminum alloy - T81 state, both for the cables used in the distribution network and for Public Lighting cables, and of hard electrolytic copper in the pre-assembled copper cables. In both cases, the section will be circular not compact. The sections required for aluminum alloy bearing neutral conductors, corresponding to each phase conductor section.

The proper installation of a power cable system represents a large part of the maintenance expense in subsequent years since depending on the care and considerations taken for such installation will be the quality of service offered.

One of the most important issues is maintenance, a rather neglected area in many industries that use power cables as a power element and must be taken seriously, which must be programmed according to the possibilities and importance of the circuit.

For the rest, it is important to note that as planned in the area of cables in recent years and its vertiginous development in both the technology used in the construction and installation, and despite its high initial cost, the installation of cables Energy will be much more requested due to the advantages obtained by opting for the use of power cables.

In the words of some experts, the standards have not been designed so that the facilities are well done, but to prevent a malfunction, avoid accidents during or after some installation, and the optimization of the installation corresponds to who designs and installs. Another criterion follows that if installation is safe and goes according to the standards, then it is a guarantee that it is well done. After all, the cost of having a human loss is invaluable and irreparable, which is why it is a primary requirement to never allow the personnel working to perform a dangerous action in order to save time or even money.

\section{Conclusion}

For the installation of a cable system it is essential to make a cost-benefit projection and from there take decisions that have to do with the material to be used as an insulating element, the conductor material, the type of joints, terminals and all its other elements, and that a wrong decision can cause great economic losses. The main care that must be considered in the installation in a cable system is that the physical integrity of the personnel performing the installation must be monitored at all times, use the right tools and respect the rules.

\section{Acknowledgments}

To colleagues who have contributed to this research, to the publisher, for allowing the article to be published. 
References

Aguirre, P. A., Lagos, C. A., Moya, S. A., Zúñiga, C., Vera-Oyarce, C., Sola, E., ... \& Bayón, J. C. (2007). Methoxycarbonylation of olefins catalyzed by palladium complexes bearing $\mathrm{P}, \mathrm{N}$-donor ligands. Dalton Transactions, (46), 5419-5426.

Bastidas Mora, HA (2005). Modeling some characteristics of electrical networks used as channels for providing telecommunications. Engineering and Research , 25 (3), 111-115.

Endesa, (2007). Americas, universidad del cono sur de las. electric transmission lines. 2015. pre-assembled cables for low voltage overhead lines. chile: sn, october 2007, endesa.

Miravalles, AF, Sancho, J., \& Ornellas, A. (2010). Collaborate among teachers to innovate in university education. Collaborate among teachers to innovate in university education , 33-43.

Miravalles, P. (2016). Management methodology, publication and optimization of continguts per e-commerce based on PrestaShop.

Rivero, S., García, M. A., \& Pinotti, A. (2010). Crosslinking capacity of tannic acid in plasticized chitosan films. Carbohydrate Polymers, 82(2), 270-276. https://doi.org/10.1016/j.carbpol.2010.04.048

Widharma, I. S., Sunaya, N., Arka, I. G. P., \& Sajayasa, M. (2017). Effect of using ground wire to lightning surge interference at $20 \mathrm{KV}$ medium voltage distribution system based on genetics algorithm. International Research Journal of Engineering, IT \& Scientific Research, 3(3), 65-76.

Giler, S. R. B., Loor, C. J. S., Moreira, J. C. M., \& Zambrano, B. A. M. (2019). Technical-economic impact of low voltage secondary lines to pre-assembled. International Journal of Physical Sciences and Engineering, 3(2), 21-26. 


\section{Biography of Authors}

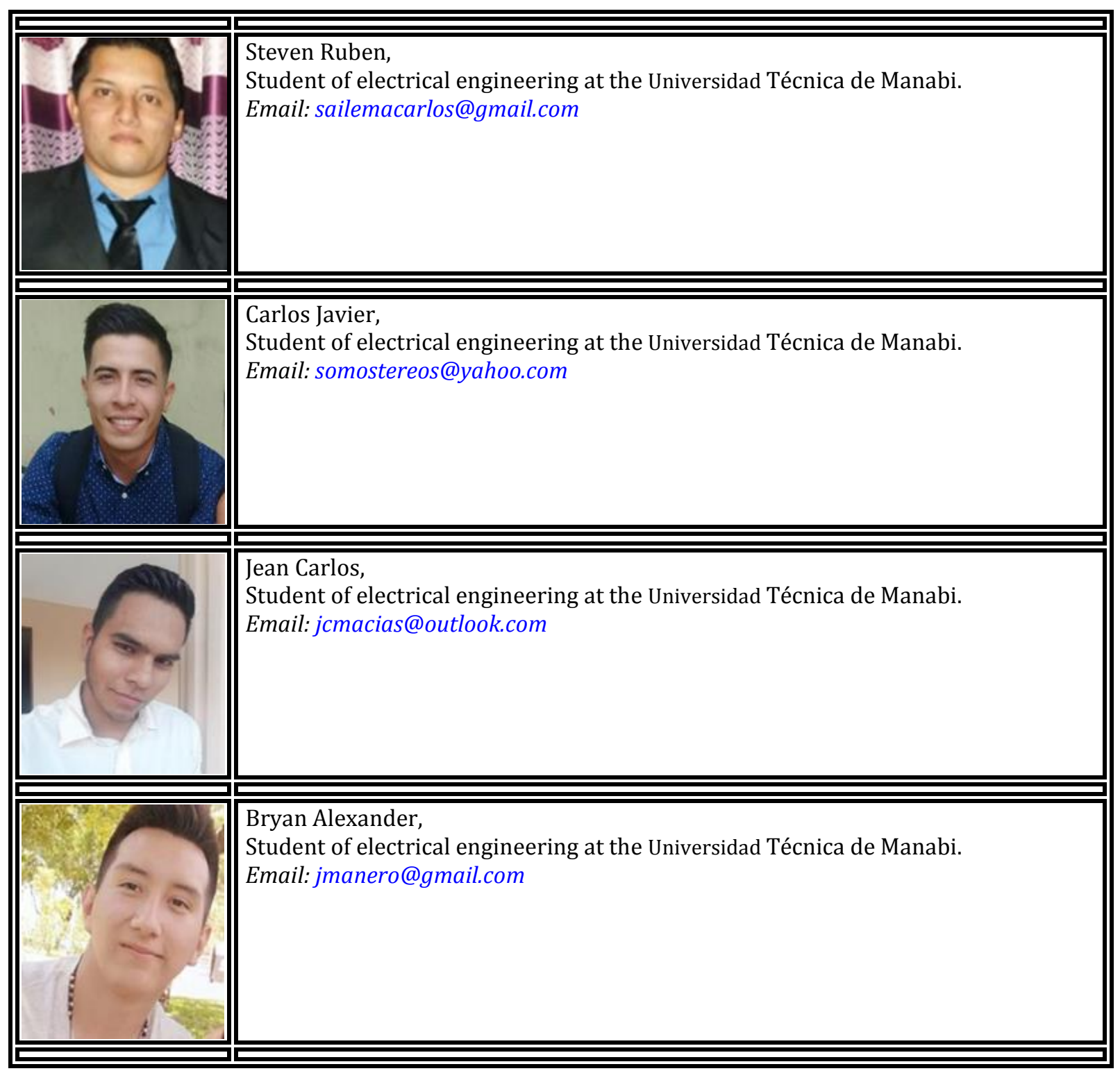

